\title{
Clinical and Genetic Risk Factors for Adverse Metabolic Outcomes in North American Testicular Cancer Survivors
}

\author{
Mohammad Abu Zaid, MDa; Wambui G. Gathirua-Mwangi, PhD ${ }^{\text {; }}$; Chunkit Fung, MDc; \\ Patrick O. Monahan, PhDa; Omar El-Charif, MS; Annalynn M. Williams, MSc; Darren R. Feldman, MD; \\ Robert J. Hamilton, MD; David J. Vaughn, MD; ; Clair J. Beard, MD ${ }^{\mathrm{h}}$; Ryan Cook, MPH${ }^{\mathrm{a}}$; \\ Sandra K. Althouse, MS ; Shirin Ardeshir-Rouhani-Fard, PharmD, MPH ${ }^{\mathrm{a}}$; Paul C. Dinh Jr, MPH; \\ Howard D. Sesso, ScD; ${ }^{i}$ Lawrence H. Einhorn, MDª Sophie D. Fossa, MD, PhD; \\ and Lois B. Travis, MD, ScD; ; for the Platinum Study Group*
}

\begin{abstract}
Background: Testicular cancer survivors (TCS) are at significantly increased risk for cardiovascular disease (CVD), with metabolic syndrome (MetS) an established risk factor. No study has addressed clinical and genetic MetS risk factors in North American TCS. Patients and Methods: TCS were aged $<55$ years at diagnosis and received first-line chemotherapy. Patients underwent physical examination, and had lipid panels, testosterone, and soluble cell adhesion molecule-1 (sICAM-1) evaluated. A single nucleotide polymorphism in rs523349 (5- $\alpha$-reductase gene, SRD5A2), recently implicated in MetS risk, was genotyped. Using standard criteria, MetS was defined as $\geq 3$ of the following: hypertension, abdominal obesity, hypertriglyceridemia, decreased high-density lipoprotein (HDL) cholesterol level, and diabetes. Matched controls were derived from the National Health and Nutrition Examination Survey. Results: We evaluated 486 TCS (median age, 38.1 years). TCS had a higher prevalence of hypertension versus controls $(43.2 \%$ vs $30.7 \% ; P<.001)$ but were less likely to have decreased HDL levels $(23.7 \%$ vs $34.8 \% ; P<.001)$ or abdominal obesity $(28.2 \%$ vs $40.1 \% ; P<.001)$. Overall MetS frequency was similar in TCS and controls $(21.0 \%$ vs $22.4 \%$; $P=.59)$, did not differ by treatment $(P=.20)$, and was not related to rs523349 $(P=.61)$. For other CVD risk factors, TCS were significantly more likely to have elevated low-density lipoprotein (LDL) cholesterol levels (17.7\% vs $9.3 \% ; P<.001)$, total cholesterol levels ( $26.3 \%$ vs $11.1 \%$; $P<.001)$, and body mass index $\geq 25 \mathrm{~kg} / \mathrm{m}^{2}(75.1 \%$ vs $69.1 \% ; P=.04)$. On multivariate analysis, age at evaluation $(P<.001)$, testosterone level $\leq 3.0 \mathrm{ng} / \mathrm{mL}$ (odds ratio [OR], 2.06; $P=.005)$, and elevated sICAM-1 level (OR highest vs lowest quartile' $\left._{3.58 ;} P=.001\right)$ were significantly associated with MetS. Conclusions and Recommendations: Metabolic abnormalities in TCS are characterized by hypertension and increased LDL and total cholesterol levels but lower rates of decreased HDL levels and abdominal obesity, signifying possible shifts in fat distribution and fat metabolism. These changes are accompanied by hypogonadism and inflammation. TCS have a high prevalence of CVD risk factors that may not be entirely captured by standard MetS criteria. Cancer treatment-associated MetS requires further characterization.
\end{abstract}

J Natl Compr Canc Netw 2018;16(3):257-265 doi: 10.6004/jncen.2017.7046

\begin{abstract}
From andiana University, Melvin and Bren Simon Cancer Center, and 'Indiana University School of Nursing, Indianapolis, Indiana; 'University of Rochester Medical Center, James P. Wilmot Cancer Institute, Rochester, New York; ${ }^{d}$ Department of Medicine, University of Chicago, Chicago, Illinois; eDepartment of Medical Oncology, Memorial Sloan Kettering Cancer Center, New York, New York; ${ }^{f}$ Division of Urology, Princess Margaret Cancer Centre, Toronto, Ontario; 'Department of Medicine, University of Pennsylvania, Philadelphia, Pennsylvania; ' of Radiation Oncology, Dana-Farber Cancer Institute, and Divisions of Preventive Medicine and Aging, Department of Medicine, Brigham and Women's Hospital, Boston, Massachusetts; and iDepartment of Oncology, Oslo University Hospital, Norwegian Radium Hospital, Oslo, Norway. *To view members of the Platinum Study Group and Platinum Study Group Advisory Committee, see eAppendices 1 and 2 (available with this article at JNCCN.org).

Submitted June 14, 2017; accepted for publication October 3, 2017.

The authors have disclosed that they have no financial interests, arrangements, affiliations, or commercial interests with the manufacturers of any products discussed in this article or their competitors.
\end{abstract}

This study was funded by NCl (R01 CA157823, to Dr. Travis). Dr. GathiruaMwangi is supported by 3R01CA196243-02S1 and K05CA175048. The $\mathrm{NCl}$ had no role in the design of the study; the collection, analysis, or interpretation of data; the writing of the manuscript; or the decision to submit the manuscript for publication.

Presented in part as an oral presentation at the 2017 Cancer Survivorship Symposium: Advancing Care and Research; January 27-28, 2017; San Diego, California. Research was also featured in a video interview in The ASCO Post Newsreels and in an article with an accompanying editorial in The ASCO Post on March 10, 2017.

Author contributions: Study concept and design: Sesso, Einhorn, Travis. Financial support: Travis. Administrative support: Travis. Provision of study materials or patients: Fung, Feldman, Hamilton, Vaughn, Beard, Einhorn, Travis. Data acquisition: Abu Zaid, Feldman, Cook, Althouse, Travis. Data analysis and interpretation: All authors. Manuscript preparation: All authors. Final approval of manuscript: All authors.

Correspondence: Lois B. Travis, MD, SCD, Indiana University, Melvin and Bren Simon Cancer Center, 535 Barnhill Drive, RT433, Indianapolis, IN 46202. E-mail: Ibtravis@iu.edu 
Testicular cancer (TC) is the most common cancer among men aged 18 to 39 years, with increasing incidence over the past 20 years. ${ }^{1}$ Cisplatin-based chemotherapy has resulted in unprecedented survival rates among patients with metastatic disease, ${ }^{2}$ with cure expected in $80 \% .^{3}$ Overall, the 5-year relative survival rate for all patients with TC is $95 \% .{ }^{4}$ As a result, 1 in 600 men in the United States is now a TC survivor (TCS), ${ }^{5}$ with a gain of upwards of 40 years of life. ${ }^{6}$ Thus, TCS comprise a unique population in which to study the long-term adverse effects of cancer treatment in survivors of adult-onset cancer. ${ }^{7}$ In particular, TCS treated with chemotherapy experience up to a 7 -fold increased long-term risk for cardiovascular disease (CVD) compared with controls. ${ }^{8-13}$

In the general population, metabolic syndrome (MetS) is a major risk factor for CVD. ${ }^{14} \mathrm{MetS}$ is a constellation of interrelated CVD risk factors, including insulin resistance, hypertension, elevated triglyceride levels, decreased high-density lipoprotein (HDL) cholesterol levels, and obesity. ${ }^{14}$ Using various definitions, European studies of TCS have reported a wide variation in the prevalence of MetS, ranging from $13 \%$ to $39 \% .{ }^{15-19}$ Some investigations have demonstrated MetS risk to be higher among TCS compared with controls, ${ }^{15-18}$ but others have not. ${ }^{19}$ Boer et $\mathrm{al}^{20}$ reported MetS to be more prevalent in TCS carrying the minor allele of a single nucleotide polymorphism (SNP), rs523349 (V89L), compared with wild-type (33\% vs $19 \% ; P=.032)$. This SNP is a nonsynonymous coding variant in the SRD5A2 gene, encoding steroid 5 - $\alpha$-reductase type II. The prevalence of MetS was particularly high $(66.7 \%)$ in TCS who had low testosterone levels $(<4.3 \mathrm{ng} / \mathrm{mL})$ and carried a minor allele (homozygous or heterozygous) genotype.

Given the conflicting data on MetS prevalence in European studies of TCS and the lack of information in North American patients, we evaluated for the first time MetS and associated risk factors among a large cohort of North American TCS. ${ }^{21}$ We also examined the reported association of the rs 523349 SNP with MetS in our patients.

\section{Patients and Methods}

\section{Participants}

The ongoing Platinum Study is evaluating the late consequences of platinum-based chemotherapy and has been approved by Institutional Review Boards at all participating institutions. ${ }^{21,22}$ Each participant provided written informed consent allowing access to medical records since cancer diagnosis. Eligibility criteria included a diagnosis of germ cell tumor (GCT) at age $<55$ years, treatment with first-line platinum-based chemotherapy, no salvage chemotherapy, no radiotherapy, and no antecedent chemotherapy for another primary cancer. All participants were disease-free at the time of clinical evaluation. We included in this analysis all TCS for whom blood samples had been analyzed and who had complete data on all MetS components.

\section{Assessments}

Sociodemographic, Lifestyle, and Behavioral Factors: TCS completed a questionnaire regarding health outcomes, lifestyle behaviors, and current prescription medications (including antihypertensive, diabetic, and lipid-lowering medications). Demographic information included age at cancer diagnosis and clinical evaluation, race, education, employment, and marital status. Smoking status was categorized as current, former, or never-smoker. Physical activity was reported as the average time per week engaged in various forms of exercise. ${ }^{23}$ Moderate- and vigorous-intensity physical activity were defined as participating in at least one activity per week with a metabolic equivalent of 3 to $<6$, or $\geq 6$ metabolic equivalents, respectively. ${ }^{24,25}$

Data Collection From Medical Records: Study staff abstracted data according to a uniform protocol, using forms adapted from a prior study. ${ }^{22}$ Data included date of GCT diagnosis, histology and site of GCT, and, for each cytotoxic drug, name, dose, dates of administration, number of cycles, and cumulative dose. All data were entered into the eClinicalWorks system (Westborough, MA), supported by the study coordinating center.

Clinical Evaluation: TCS underwent a physical examination measuring height, weight, and waist circumference. Body mass index (BMI) was calculated as $\mathrm{kg} / \mathrm{m}^{2}$. Blood pressure was measured twice after resting for 5 minutes and then averaged. Blood samples were drawn, time of last meal was recorded, and the samples were frozen and shipped to the central laboratory. Serum levels of testosterone, luteinizing hormone, lipids, creatinine, and soluble cell 
adhesion molecule-1 (sICAM-1), a known CVD biomarker, ${ }^{26-28}$ were measured using commercial assays. Hypogonadism was defined using the FDA definition (total serum testosterone $\leq 3.0 \mathrm{ng} / \mathrm{mL}$ ), ${ }^{29}$ which is commonly used in clinical practice.

DNA Genotyping and Imputation: DNA was extracted from blood samples collected at clinical evaluation. SNPs were genotyped on the HumanOmniExpressExome-8 BeadChip (Illumina, Inc., San Diego, CA) at the RIKEN Center for Integrative Medical Sciences. Because the SNP of interest is not called on this chip, we performed genotype imputation following standard quality control measures as previously described. ${ }^{30}$ Imputation was performed on the University of Michigan Imputation Server ${ }^{31}$ with the following parameters: 1000 Genomes Phase 1 (version 3) Shapeit2 (no singletons) reference panel, SHAPEIT phasing, and the EUR (European) population. Linkage disequilibrium (LD) structures around the variant of interest were determined using NIH's LDlink $^{32}$ using the CEU (European) population.

\section{Definition of MetS}

MetS was defined using a modification of the $\mathrm{Na}$ tional Cholesterol Education Program's Adult Treatment Panel III (NCEP ATP III) Guidelines ${ }^{14}$ as the presence of $\geq 3$ of the following (Table 1): (1) systolic blood pressure $\geq 130 \mathrm{~mm} \mathrm{Hg}$ and/or diastolic blood pressure $\geq 85 \mathrm{~mm} \mathrm{Hg}$ or use of antihypertensive medication; (2) abdominal obesity (waist circumference $\geq 102 \mathrm{~cm}$ ); (3) self-reported diabetes and medication use; (4) HDL cholesterol level $<40 \mathrm{mg} / \mathrm{dL}$ or lipidlowering medication; and/or (5) serum triglyceride level $\geq 150 \mathrm{mg} / \mathrm{dL}$ (fasting) or $\geq 175 \mathrm{mg} / \mathrm{dL}$ (nonfasting). These MetS criteria were developed by several major organizations to represent one harmonized definition. ${ }^{14}$ Criteria for HDL and triglyceride cut points were adapted from recent guidelines. ${ }^{33}$

\section{Control Group}

Matched controls for selected comparisons were chosen from the National Health and Nutrition Examination Survey (NHANES) using 2 consecutive data sets (2011-2012 and 2013-2014), following methods applied by the St. Jude's Lifetime Cohort study. ${ }^{34}$ Controls (restricted to men without cancer) were matched $1: 1$ on race, age (within 5 years), and educational level.

\begin{tabular}{|c|c|c|}
\hline Measure & $\begin{array}{l}\text { Modified NCEP ATP } \\
\text { III Criteria for Met5 }{ }^{14}\end{array}$ & Definition Used for Current Study \\
\hline Elevated BP & $\begin{array}{l}\mathrm{BP}_{\text {systolic }} \geq 130 \mathrm{~mm} \mathrm{Hg} \\
\text { and/or } \\
\mathrm{BP}_{\text {diastolic }} \geq 85 \mathrm{~mm} \mathrm{Hg} \\
\text { or } \\
\text { Drug treatment for } \\
\text { hypertension }\end{array}$ & $\begin{array}{l}\mathrm{BP}_{\text {systolic }} \geq 130 \mathrm{~mm} \mathrm{Hg} \\
\text { and/or } \\
\mathrm{BP}_{\text {diastolic }} \geq 85 \mathrm{~mm} \mathrm{Hg} \\
\text { or } \\
\text { Drug treatment for hypertension }\end{array}$ \\
\hline $\begin{array}{l}\text { Elevated waist } \\
\text { circumference }\end{array}$ & $\begin{array}{l}\text { Population- and } \\
\text { country-specific } \\
\text { definitions: } \\
\text { US } \geq 102 \mathrm{~cm} \text { in men }\end{array}$ & $\geq 102 \mathrm{~cm}$ \\
\hline $\begin{array}{l}\text { Elevated } \\
\text { fasting glucose }\end{array}$ & $\geq 100 \mathrm{mg} / \mathrm{dL}$ & $\begin{array}{l}\text { Self-reported diabetes } \\
\text { and } \\
\text { Taking drug treatment for diabetes }\end{array}$ \\
\hline Reduced HDL & $\begin{array}{l}<40 \mathrm{mg} / \mathrm{dL} \text { in men } \\
\text { or } \\
\text { Drug treatment for } \\
\text { reduced HDL }\end{array}$ & $\begin{array}{l}<40 \mathrm{mg} / \mathrm{dL} \\
\text { or } \\
\text { Drug treatment for reduced } \mathrm{HDL} \\
\text { (including statins, fibrates } \\
\text { and nicotinic acid)c }\end{array}$ \\
\hline $\begin{array}{l}\text { Elevated } \\
\text { triglycerides }\end{array}$ & $\begin{array}{l}\geq 150 \mathrm{mg} / \mathrm{dL} \\
\text { or } \\
\text { Drug treatment } \\
\text { for elevated } \\
\text { triglycerides }\end{array}$ & $\begin{array}{l}\geq 150 \mathrm{mg} / \mathrm{dL} \text { (fasting) } \\
\text { or } \\
\geq 175 \mathrm{mg} / \mathrm{dL} \text { (nonfasting) } \\
\text { or } \\
\text { Drug treatment for elevated } \\
\text { triglycerides }^{d}\end{array}$ \\
\hline Mets & $\geq 3$ criteria & $\geq 3$ criteria \\
\hline
\end{tabular}

Abbreviations: BP, blood pressure; HDL, high-density lipoprotein cholesterol; MetS, metabolic syndrome; NCEP ATP III, National Cholesterol Education Program Adult Treatment Panel III.

aStudy participants were asked, "Have you ever taken prescription medications for high BP?" This criterion was considered met if participants answered "yes, current

use." told you that you had one of the following conditions, or have you ever had one of the following procedures: (1) diabetes requiring insulin, (2) diabetes requiring tablets or pills?" This criterion was considered met if the participant answered "yes" to either question. Haugnes et $\mathrm{al}^{19}$ used a similar definition but substituted "or" for "and." Neither Haugnes et al ${ }^{19}$ nor the current study measured fasting

glucose.
'Cutoff for nonfasting measurements based on joint consensus statement of 'Cutoff for nonfasting measurements based on joint consensus statement of
European Atherosclerosis Society and European Federation of Clinical Chemistry and Laboratory Medicine. ${ }^{38}$

dStudy participants were asked, "Have you ever taken prescription medications for high cholesterol?" This criterion was considered met if participants answered "yes, current use." This may have included statins, fibrates, and/or nicotinic acid.

\section{Statistical Analyses}

Data were summarized, with medians (ranges) for continuous variables and proportions for categorical variables in 2 TCS subgroups defined by the presence or absence of MetS. The 2 groups were compared using the Pearson chi-square and 2-sided Wilcoxon rank sum tests on categorical and continuous variables, respectively. TCS were compared with controls using the Pearson chi-square test with regard to the prevalence of various MetS components, as well as other CVD risk factors not included in the NCEP ATP III criteria. A composite score was calculated based on the cut points for the individual MetS components, with a range of 0 to 5 ( 0 indicated no abnormal components). Based on MetS diagnostic criteria, ${ }^{14}$ participants with a composite score of 3 to 5 were classified with MetS. 
To determine factors associated with MetS in TCS, a 2-step approach was used. First, logistic regression models were used to estimate the odds ratios (ORs), 95\% confidence intervals (CIs), and $P$ values for all clinical, demographic, behavioral, and laboratory measures. Second, factors that were significantly associated with MetS in univariate analyses were included in the multivariable model. All statistical analyses were conducted using SAS 9.4 (SAS Institute, Cary, NC). All tests were 2 -sided, with $P$ values $<.05$ considered statistically significant.

\section{Results}

\section{TCS Characteristics}

Median time from chemotherapy completion to study enrollment was 4.7 years (range, 0.4-23.9). TCS with MetS $(n=102)$ were significantly older at clinical evaluation compared with those without MetS ( $n=384$; median, 44.4 vs 36.6 years; $P<.001$ ) (supplemental eTable 1, available with this article at INCCN.org). TCS received either bleomycin/etoposide/cisplatin (BEP; $54.7 \%$ ) or etoposide/cisplatin (EP; 33.1\%), but MetS prevalence did not differ by treatment regimen nor by cumulative dose of cisplatin or bleomycin. TCS with MetS had a significantly higher prevalence of obesity $(60.8 \%$ vs $22.7 \%$; $P<.001$ ), hypogonadism (46.1\% vs $26.8 \% ; P<.001$ ), and elevated sICAM levels compared with those without MetS (supplemental eTable 2).

\section{Comparison With Matched Controls}

TCS were more likely to have hypertension $(43.2 \%$ vs $30.7 \% ; P<.001)$ but less likely to have low HDL levels $(23.7 \%$ vs $34.8 \% ; P<.001)$ and abdominal obesity $(28.2 \%$ vs $40.1 \%$; $<.001)$ compared with controls (Table 2). Although overall MetS prevalence in TCS and controls was comparable $(21.0 \%$ vs $22.4 \% ; P=.59)$, there were significant differences in other CVD risk factors not included in the NCEP ATP III definition. TCS were more likely to have low-density lipoprotein (LDL) cholesterol levels $\geq 160 \mathrm{mg} / \mathrm{dL}(17.7 \%$ vs $9.3 \%$; $P<.001)$, total cholesterol levels $\geq 240 \mathrm{mg} / \mathrm{dL}$ ( $26.3 \%$ vs $11.1 \% ; P<.001$ ), and $\mathrm{BMI} \geq 25 \mathrm{~kg} / \mathrm{m}^{2}$ (75.1\% vs $\left.69.1 \% ; P=.04\right)$. Additionally, a larger proportion of TCS compared with controls reported participating in moderate- $(93.8 \%$ vs $42.4 \% ; P<.001)$ or vigorous-intensity $(66.7 \%$ vs

\begin{tabular}{|c|c|c|c|}
\hline & $\begin{array}{l}\text { Platinum Study } \\
\text { n (\%) }\end{array}$ & $\begin{array}{l}\text { NHANES } \\
\mathrm{n}(\%)\end{array}$ & $P$ Value $^{\mathrm{b}}$ \\
\hline Total, N & 486 & 486 & \\
\hline \multicolumn{4}{|l|}{ Components of MetS } \\
\hline \multicolumn{4}{|l|}{$\mathrm{BP}$} \\
\hline Elevated or on medication & $210(43.2)$ & $149(30.7)$ & \multirow[b]{2}{*}{$<.001$} \\
\hline $\begin{array}{l}\text { Normal (systolic }<130 \mathrm{~mm} \\
\mathrm{Hg} \text {, diastolic }<85 \mathrm{~mm} \mathrm{Hg} \text {, } \\
\text { and not on medication) }\end{array}$ & $276(56.8)$ & $337(69.3)$ & \\
\hline \multicolumn{4}{|l|}{ Waist circumference } \\
\hline$\geq 102 \mathrm{~cm}$ & $137(28.2)$ & $195(40.1)$ & \multirow{2}{*}{$<.001$} \\
\hline$<102 \mathrm{~cm}$ & $349(71.8)$ & $291(59.9)$ & \\
\hline \multicolumn{4}{|c|}{ Diagnosis of diabetes and use of medication } \\
\hline Yes & $19(3.9)$ & $21(4.3)$ & \multirow{2}{*}{.75} \\
\hline No & $467(96.1)$ & $465(95.7)$ & \\
\hline \multicolumn{4}{|l|}{ HDL cholesterol } \\
\hline $\begin{array}{l}\text { Low }(<40 \mathrm{mg} / \mathrm{dL}) \text { or on } \\
\text { medicationc }\end{array}$ & $115(23.7)$ & $169(34.8)$ & \multirow{2}{*}{$<.001$} \\
\hline $\begin{array}{l}\text { Normal ( } \geq 40 \mathrm{mg} / \mathrm{dL} \text { and not } \\
\text { on medication) }\end{array}$ & $371(76.3)$ & $317(65.2)$ & \\
\hline \multicolumn{4}{|l|}{ Triglycerides $^{\mathrm{d}}$} \\
\hline Elevated or on medication ${ }^{c}$ & $195(40.1)$ & $174(35.8)$ & \multirow{2}{*}{.17} \\
\hline Normal & $291(59.9)$ & $312(64.2)$ & \\
\hline \multicolumn{4}{|l|}{ MetS } \\
\hline Yes ( $\geq 3$ components) & $102(21.0)$ & $109(22.4)$ & \multirow{2}{*}{.59} \\
\hline No (<3 components) & $384(79.0)$ & $377(77.6)$ & \\
\hline \multicolumn{4}{|c|}{ Number of abnormal MetS components } \\
\hline 0 & $151(31.1)$ & $154(31.7)$ & \multirow{6}{*}{.58} \\
\hline 1 & $142(29.2)$ & $120(24.7)$ & \\
\hline 2 & $91(18.7)$ & $103(21.2)$ & \\
\hline 3 & $64(13.2)$ & $62(12.8)$ & \\
\hline 4 & $30(6.2)$ & $39(8.0)$ & \\
\hline 5 & $8(1.7)$ & $8(1.6)$ & \\
\hline \multicolumn{4}{|c|}{ CVD risk factors not included in the MetS definition } \\
\hline \multicolumn{4}{|c|}{ Body mass index, $\mathrm{kg} / \mathrm{m}^{2}$} \\
\hline$\geq 25$ (overweight or obese) & $365(75.1)$ & $336(69.1)$ & \multirow{2}{*}{.04} \\
\hline$<25$ (normal) & $121(24.9)$ & $150(30.9)$ & \\
\hline \multicolumn{4}{|l|}{ Total cholesterol, mg/dL } \\
\hline$\geq 240$ & $128(26.3)$ & $54(11.1)$ & \multirow{2}{*}{$<.001$} \\
\hline$<240$ & $358(73.7)$ & $432(88.9)$ & \\
\hline \multicolumn{4}{|l|}{ LDL cholesterol, mg/dLe } \\
\hline$\geq 160$ & $86(17.7)$ & $43(9.3)$ & \multirow{2}{*}{$<.001$} \\
\hline$<160$ & $400(82.3)$ & $418(90.7)$ & \\
\hline Smoking status & & & \\
\hline Never-smoker & $273(56.2)$ & $248(51.0)$ & \\
\hline Former smoker & $167(34.4)$ & $112(23.1)$ & $<.001$ \\
\hline Current smoker & $45(9.3)$ & $126(25.9)$ & \\
\hline Not stated & $1(0.2)$ & $0(0)$ & \\
\hline Moderate-intensity physical acti & ty $(3 \text { to }<6 \mathrm{METs})^{\dagger}$ & & \\
\hline No & $27(5.6)$ & $280(57.6)$ & $<001$ \\
\hline Yes & $456(93.8)$ & $206(42.4)$ & $<.001$ \\
\hline Not stated & $3(0.6)$ & $0(0)$ & \\
\hline Vigorous-intensity physical activ & $(\geq 6 \mathrm{METS})^{f}$ & & \\
\hline No & $159(32.7)$ & $323(66.5)$ & $<001$ \\
\hline Yes & $324(66.7)$ & $163(33.5)$ & $<.001$ \\
\hline Not stated & $3(0.6)$ & $0(0)$ & \\
\hline
\end{tabular}

Abbreviations: BP, blood pressure; CVD, cardiovascular disease; HDL, high-density lipoprotein; LDL, low-density lipoprotein; METs, metabolic equivalents; MetS, metabolic syndrome; NHANES, National Health and Nutrition Examination Survey. aplease refer to Methods for definition of MetS. Controls were matched 1:1 on age (within 5 years), race, and educational level with men from NHANES.

${ }^{b} P$ values obtained from Pearson chi-square test. Statistically significant $P$ values are bolded.

'Patients were asked if they had ever taken prescription medications for high cholesterol. These may have included statins, fibrates, and/or nicotinic acid.

${ }^{\mathrm{d} C u t o f f}$ points for elevated triglycerides are $150 \mathrm{mg} / \mathrm{dL}$ for those who had fasted for $\geq 8$ hours, and $175 \mathrm{mg} / \mathrm{dL}$ for those who had $<8$ hours of fasting prior to blood sample collection ${ }^{38}$

e 25 participants in the NHANES cohort had missing data on LDL cholesterol. ${ }^{\mathrm{f}}$ The vigorous- and moderate-intensity physical activity groups are not mutually exclusive. There are a total of 9 different activities surveyed in the Platinum Study, some of which are moderate-intensity and some of which are vigorous-intensity. some of which are moderate-intensity and some of which are vigorous-intensity.
If a subject reported that he spent 1 hour walking a week (ie, moderate-intensity If a subject reported that he spent 1 hour walking a week (ie, moderate-intensity
activity) and 30 minutes running per week (ie, vigorous-intensity activity), he was activity) and 30 minutes running per week (ie, vigorous-intensity activity), he was
included as a yes for both "any moderate" and "any vigorous" activity. ${ }^{23,24}$ Three survivors did not provide data on physical activity. 
$33.5 \% ; P<.001)$ physical activity, and were less likely to be current smokers $(9.3 \%$ vs $25.9 \% ; P<.001)$.

\section{Factors Associated With MetS in TCS}

Results of a univariate analysis of factors potentially associated with MetS are shown in Table 3. Factors statistically significant on univariate analysis were incorporated into a multivariate model, in which age, low serum testosterone level, and sICAM level remained significantly associated with MetS (Table 4). For every 10-year increase in age at clinical evaluation, MetS risk increased by 1.7 -fold $(95 \%$ CI, 1.33-2.30; $P<.001)$. Testosterone level $\leq 3.0 \mathrm{ng} /$ $\mathrm{mL}$ was associated with a significant 2 -fold increased risk of MetS compared with higher levels $(P=.005)$. MetS risk increased monotonically with increasing sICAM level (OR, 3.58 comparing highest vs lowest quartile; $P=.001)$. Educational level, marital status, alcohol intake, and vigorous-intensity physical activity were not associated with MetS risk in the multivariate model.

\section{Genetic Association of MetS With SRD5A2}

The SNP rs523349 showed high imputation quality $\left(\mathrm{R}^{2}=1\right)$, call rate $(>0.99)$, and perfect HardyWeinberg equilibrium $(P=1.0)$. This imputed SNP was in perfect LD with a nearby genotyped SNP, rs12467911. LDlink revealed that the expected LD $\mathrm{R}^{2}$ in a European population is 0.975 . Genotype frequencies by MetS status are presented in Table 5 . The variant genotype did not correlate with MetS $(P=.61)$.

\section{Discussion}

Our investigation represents the largest to date to address the prevalence of metabolic abnormalities in TCS treated with contemporary platinum-based regimens and is the only investigation of North American patients. At a median age of only 38 years, 3 in 4 TCS were overweight or obese, $43 \%$ had hypertension, and a significantly higher proportion had elevated LDL or total cholesterol levels compared with matched controls. Overall, 1 in 5 TCS had MetS according to the NCEP ATP III definition. ${ }^{14}$ No difference was seen in the prevalence of MetS by treatment regimen (BEP vs EP) nor by cumulative dose of cisplatin or bleomycin. Significant risk factors for MetS included hypogonadism, increasing

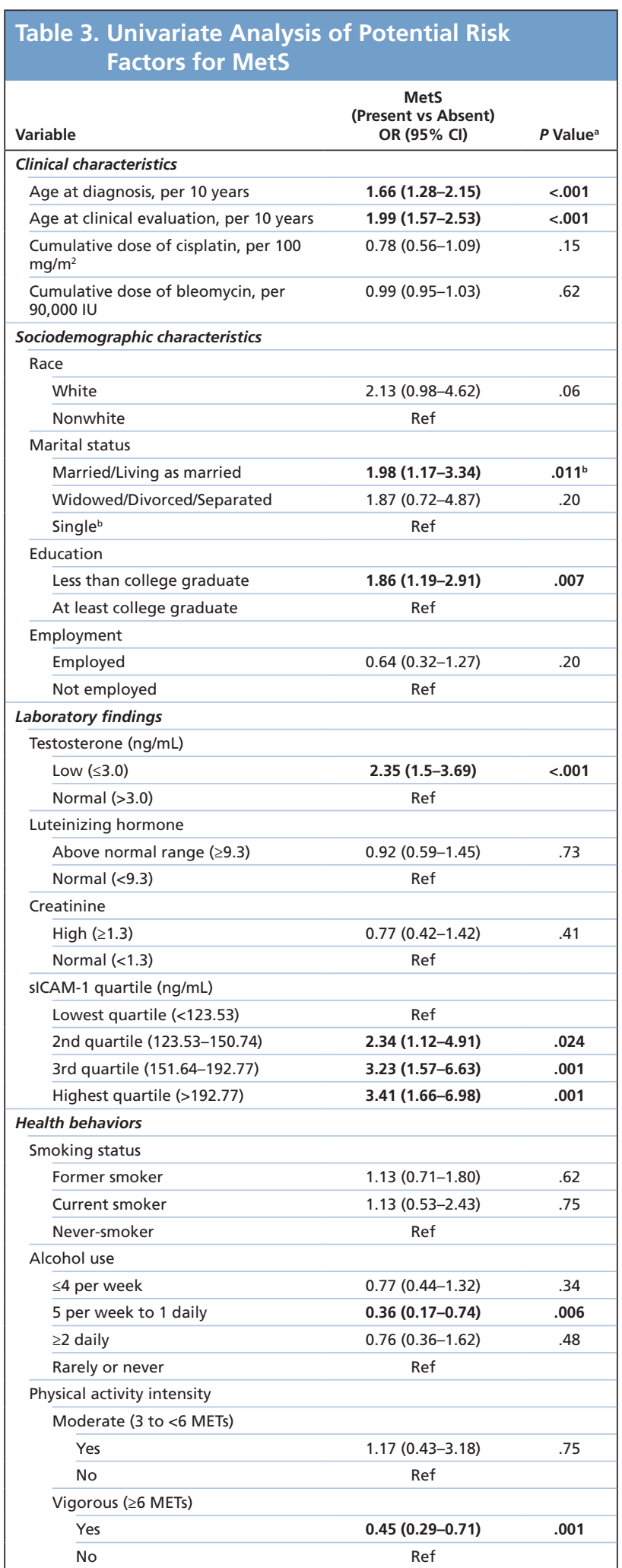

Abbreviations: METs, metabolic equivalents; MetS, metabolic syndrome; sICAM-1, serum soluble cell adhesion molecule-1.

astatistically significant $P$ values are bolded.

bThe apparent protective effect of single status is likely due to these participants being younger. The correlation is not significant when marital status is adjusted for age at clinical evaluation. 
Abu Zaid et al

\begin{tabular}{|c|c|c|c|}
\hline Clinical Factor & OR & $95 \% \mathrm{Cl}$ & $P$ Value \\
\hline \multicolumn{4}{|l|}{ Clinical and sociodemographic characteristics } \\
\hline Age at clinical evaluation, per 10 years & $1.75^{\mathrm{b}}$ & $1.33-2.30$ & $<.001$ \\
\hline \multicolumn{4}{|l|}{ Education } \\
\hline Not college graduate & 1.51 & $0.91-2.51$ & .11 \\
\hline College or post graduate & - & - & Ref \\
\hline \multicolumn{4}{|l|}{ Marital status } \\
\hline Not married & 0.88 & $0.51-1.49$ & .62 \\
\hline Married/Living as married & - & - & Ref \\
\hline \multicolumn{4}{|l|}{ Laboratory findings } \\
\hline \multicolumn{4}{|l|}{ Serum testosterone $(\mathrm{ng} / \mathrm{mL})$} \\
\hline Low $(\leq 3.0)$ & 2.06 & $1.25-3.39$ & .005 \\
\hline Normal $(>3.0)$ & - & - & Ref \\
\hline \multicolumn{4}{|l|}{ sICAM-1 (ng/mL) } \\
\hline Lowest quartile $(<124)$ & - & - & Ref \\
\hline 2nd quartile (124-151) & 2.73 & $1.24-6.06$ & .01 \\
\hline 3rd quartile (152-193) & 3.21 & $1.48-6.95$ & .003 \\
\hline Highest quartile (>193) & 3.58 & $1.66-7.75$ & .001 \\
\hline \multicolumn{4}{|l|}{ Health behaviors } \\
\hline \multicolumn{4}{|c|}{ Average number of alcoholic drinks in past year } \\
\hline$\leq 4$ per week & 0.85 & $0.46-1.56$ & .60 \\
\hline 5 per week to 1 daily & 0.47 & $0.21-1.05$ & .07 \\
\hline$\geq 2$ daily & 0.73 & $0.31-1.69$ & .46 \\
\hline Rarely or never & - & - & Ref \\
\hline \multicolumn{4}{|l|}{ Vigorous-intensity physical activity ( $\geq 6$ METs) } \\
\hline Yes & 0.84 & $0.49-1.44$ & .53 \\
\hline No & - & - & Ref \\
\hline
\end{tabular}

Abbreviations: METs, metabolic equivalents; ORs, odds ratios; sICAM-1, serum soluble cell adhesion molecule-1.

${ }^{a}$ For the multinomial logistic regression analyses, 18 survivors were excluded due to unavailable data for $\geq 1$ variables.

${ }^{b}$ Bold indicates ORs with $P<.05$.

age, and increasing sICAM level. No association with MetS was observed with the variant genotype for rs523349.

Westerink et $\mathrm{al}^{35}$ recently pointed out that the etiology of cancer treatment-induced MetS (CTIMetS) differs from MetS in the general population, where sedentary lifestyle, along with excess caloric intake, are the primary causes. ${ }^{14}$ In contrast, CTIMetS is multifactorial and differs by cancer diagnosis, treatment, and patient characteristics. Surgery, ${ }^{36,37}$ radiotherapy, ${ }^{38}$ chemotherapy, ${ }^{18,19,39}$ and hormonal therapy $^{40-44}$ have each been shown to induce CTIMetS. In TCS, hypogonadism and chemotherapy, rather than sedentary behavior, are likely the main causes for metabolic abnormalities. The TCS in our study were at least twice more likely than controls to engage in moderate- or vigorous-intensity physical activity. Despite this, we did not find a significant difference in the prevalence of MetS between TCS and NHANES controls, likely because MetS criteria originally developed for the general population ${ }^{14}$ does not reflect the full spectrum of metabolic abnormalities seen in TCS.

The relationships between hypogonadism with MetS and CVD in the general population ${ }^{45-50}$ and TCS $^{13,16-19}$ are well-established. In our study, approximately one-third of survivors were hypogonadal, which is higher than reported in the general population $^{51}$ but not unexpected because our participants had undergone orchiectomy. In our cohort, TCS with hypogonadism were twice as likely to have MetS in multivariate analysis. Hypogonadism also correlated with obesity, hypertension, and high LDL and total cholesterol levels in univariate analysis (data not shown). Hypogonadism may also explain the lower prevalence of low HDL in TCS compared with controls because androgens can have a suppressive effect on HDL..$^{52}$ In addition, the smaller waist circumference in TCS compared with controls, while having a higher BMI, may be explained by increased femoral adipose tissue deposition observed in hypogonadal compared with eugonadal patients..$^{53}$

Table 5. Comparison of Prevalence of MetS in Genotype Groups for SNP rs523349 (V89L) in SRD5A2 Gene

\begin{tabular}{|c|c|c|c|c|c|c|}
\hline & \multicolumn{3}{|c|}{ Boer et $\mathrm{al}^{20}(\mathrm{n}=173)$} & \multicolumn{3}{|c|}{ Platinum Study $(n=405)$} \\
\hline & $\begin{array}{l}\text { Wild-Type (VV) } \\
(n=91 ; 52.6 \%)\end{array}$ & $\begin{array}{l}\text { Variant (VL/LL) } \\
(n=82 ; 47.4 \%)^{a}\end{array}$ & $P$ Value & $\begin{array}{l}\text { Wild-Type (VV) } \\
(\mathrm{n}=196 ; 48.4 \%)\end{array}$ & $\begin{array}{c}\text { Variant (VL/LL) } \\
(n=209 ; 51.6 \%)^{b}\end{array}$ & $P$ Value \\
\hline Mets: all survivors & $19 \%$ & $33 \%$ & .03 & $20 \%$ & $22 \%$ & .61 \\
\hline MetS: testosterone $<4.3 \mathrm{ng} / \mathrm{mL}$ & $33 \%$ & $67 \%$ & NR & $26 \%$ & $25 \%$ & .98 \\
\hline MetS: testosterone $\geq 4.3 \mathrm{ng} / \mathrm{mL}$ & $17 \%$ & $20 \%$ & NR & $16 \%$ & $19 \%$ & .60 \\
\hline
\end{tabular}

Abbreviations: HDL, high-density lipoprotein; MetS, metabolic syndrome; NR, not reported; SNP, single nucleotide polymorphism; TCS, testicular cancer survivors.

a 64 TCS with heterozygous (VL) genotype and 18 with homozygous (LL) genotype.

177 TCS with heterozygous (VL) genotype and 32 with homozygous (LL) genotype.

'For assessment of MetS, Boer et al ${ }^{20}$ used the American Heart Association/National Heart, Lung, and Blood Institute (AHA/NHLBI) classification ${ }^{67}$ with MetS diagnosed if $\geq 3$ of the following criteria were present: central obesity (waist circumference $\geq 102 \mathrm{~cm}$ ), high triglyceride level $(\geq 1.7 \mathrm{mmol} / \mathrm{L}[\geq 150 \mathrm{mg} / \mathrm{dL}$ ] or on medication), low HDL cholesterol level ( $<1.03 \mathrm{mmol} / \mathrm{L}[<40 \mathrm{mg} / \mathrm{dL}$ ] or on medication), high blood pressure (systolic $\geq 130 \mathrm{~mm} \mathrm{Hg}$ or diastolic $\geq 85 \mathrm{~mm} \mathrm{Hg}$ or on medication), and high glucose level ( $\geq 5.6 \mathrm{mmol} / \mathrm{L}$ $[100 \mathrm{mg} / \mathrm{dL}]$ or on medication). 
Studies of the effect of testosterone replacement on MetS and CVD risk in TCS are sparse. Although such investigations in older men in the general population showed favorable effects on lipid metabolism, bone mineral density, muscle mass, and fat-free body mass, ${ }^{54,55}$ the effects of testosterone replacement on CVD risk have been conflicting..$^{56}$ One clinical trial showed an excess of CVD adverse events in older men treated with testosterone compared with placebo, ${ }^{57}$ but another trial in a similar population did not. ${ }^{58}$ However, these findings may not apply to young and physically active TCS. For young TCS with symptomatic hypogonadism, testosterone replacement should be considered, and future research is needed to address both the benefits and risks of testosterone replacement therapy.

Inflammation is considered a critical pathogenic component of atherosclerosis..$^{59}$ de Haas et $\mathrm{al}^{17}$ provided a comprehensive assessment of proinflammatory markers in chemotherapy-treated TCS, finding significantly elevated levels of several markers in patients with MetS versus those without. Herein, we found that sICAM levels increased with increasing MetS risk even after adjustment for age and additional risk factors in multivariate analysis. sICAM is an adhesion molecule that serves a critical role in the adhesion and transmigration of leucocytes across the endothelial wall, an early step in the formation of the atherosclerotic plaque. ${ }^{60}$ Epidemiologic studies have shown strong, positive associations between sICAM levels and future CVD events in apparently healthy men and women. ${ }^{26-28}$ Vaughn et al ${ }^{61}$ reported sICAM levels to be higher in TCS treated with chemotherapy than with surgery alone, suggesting a direct mechanism for CVD through chemotherapyinduced endothelial dysfunction. In vitro studies further support this hypothesis. ${ }^{62-64}$

There has been increasing interest in personalizing care for cancer survivors. One approach is to identify genetic variants that can predispose survivors to selected adverse health outcomes. ${ }^{7}$ In this study, we evaluated an SNP (rs523349) in the steroid 5- $\alpha$-reductase type II gene recently associated with MetS in TCS..$^{20}$ This SNP decreases enzyme activity and thus the conversion of testosterone to the more active metabolite dihydrotestosterone. ${ }^{65}$ The frequencies of the wild-type and variant rs523349 in our cohort were comparable to those in Boer et $\mathrm{al}^{20}$ (Table 5); however, in our cohort, with more than twice the sample size, we found no association with MetS. An approach that accounts for multiple genes involved in relevant pathways may better identify clinically actionable results that could inform riskadapted management approaches.

The prevalence of MetS in our patients is within the range $(17 \%-41 \%)$ reported in European studies of platinum-treated TCS (summarized in supplemental eTable 3). ${ }^{13,15-19}$ Although each European series used slightly different criteria for MetS than applied in this study, it is still possible to compare the prevalence of individual MetS components. The most pronounced component of MetS among our TCS was hypertension (43\%). Haugnes et $\mathrm{al}^{19}$ found significantly increased risks of hypertension in patients treated with cisplatin compared with those treated surgically ( $\geq 45 \%$ vs $34 \%$, respectively), as did Willemse et $\mathrm{al}^{18}$ (31\% vs $14 \%$, respectively). The association between cisplatin-based chemotherapy, hypertension, and CVD in TCS is well-established, and is reviewed elsewhere. ${ }^{7,64}$

\section{Strengths and Limitations}

Strengths of our study include the large number of patients, detailed medical chart abstraction, and use of contemporary and homogeneous platinum-based chemotherapy regimens. We used a definition for hypogonadism that is clinically relevant and easily applicable to clinical practice.

However, any cross-sectional design has potential limitations and does not allow us to infer causation of evaluated risk factors to MetS, although prospective data collection is planned for this cohort. Additionally, the SNP of interest was imputed and not genotyped, although it was in perfect LD with a nearby genotyped SNP. Our study participants also largely represent well-educated TCS followed at major academic institutions, and the prevalence of MetS may be higher in community-based settings. Moreover, participants in the population-based NHANES cohort may not be comparable to our TCS in terms of all relevant sociodemographic and lifestyle variables.

\section{Conclusions and Recommendations}

There is a high prevalence of metabolic abnormalities in TCS treated with chemotherapy at a relatively young age and shortly after completion of cancer 
treatment. The etiology of MetS in cancer survivors likely differs from the general population,,$^{35}$ thus, applying criteria developed for the general population to cancer survivors may underestimate CVD risk. Importantly, longitudinal cohort studies of survivors are needed to develop more accurate risk prediction models for CVD. Meanwhile, it is reasonable to assume that management strategies for components of MetS may have similar positive effects on CVD prevention. Providers are encouraged to screen and adequately treat TCS for hypertension, dyslipidemia, and hypogonadism. Further, all TCS should be encouraged to adopt practices consistent with a healthy lifestyle, including maintenance of ideal body weight, avoidance of tobacco use, and engagement in regular exercise.

\section{References}

1. Nigam M, Aschebrook-Kilfoy $B$, Shikanov S, Eggener S. Increasing incidence of testicular cancer in the United States and Europe between 1992 and 2009. World J Urol 2015;33:623-631.

2. Einhorn LH, Donohue J. Cis-diamminedichloroplatinum, vinblastine, and bleomycin combination chemotherapy in disseminated testicular cancer. Ann Intern Med 1977;87:293-298.

3. Hanna NH, Einhorn LH. Testicular cancer-discoveries and updates. N Engl J Med 2014;371:2005-2016.

4. Verdecchia A, Francisci S, Brenner H, et al. Recent cancer survival in Europe: a 2000-02 period analysis of EUROCARE-4 data. Lancet Oncol 2007;8:784-796.

5. Miller KD, Siegel RL, Lin CC, et al. Cancer treatment and survivorship statistics, 2016. CA Cancer J Clin 2016;66:271-289.

6. Capocaccia R, Gatta G, Dal Maso L. Life expectancy of colon, breast, and testicular cancer patients: an analysis of US-SEER population-based data. Ann Oncol 2015;26:1263-1268.

7. Travis LB, Beard C, Allan JM, et al. Testicular cancer survivorship: research strategies and recommendations. J Natl Cancer Inst 2010;102:1114-1130.

8. Fung C, Fossa SD, Milano MT, et al. Cardiovascular disease mortality after chemotherapy or surgery for testicular nonseminoma: a population-based study. J Clin Oncol 2015;33:3105-3115.

9. Haugnes HS, Wethal $\mathrm{T}$, Aass $\mathrm{N}$, et al. Cardiovascular risk factors and morbidity in long-term survivors of testicular cancer: a 20-year follow-up study. J Clin Oncol 2010;28:4649-4657.

10. Huddart RA, Norman A, Shahidi M, et al. Cardiovascular disease as a long-term complication of treatment for testicular cancer. J Clin Oncol 2003;21:1513-1523.

11. Meinardi MT, Gietema JA, van der Graaf WT, et al. Cardiovascular morbidity in long-term survivors of metastatic testicular cancer. J Clin Oncol 2000;18:1725-1732.

12. van den Belt-Dusebout AW, de Wit R, Gietema JA, et al. Treatmentspecific risks of second malignancies and cardiovascular disease in 5-year survivors of testicular cancer. J Clin Oncol 2007;25:4370-4378.

13. de Haas EC, Oosting SF, Lefrandt JD, et al. The metabolic syndrome in cancer survivors. Lancet Oncol 2010;11:193-203.

14. Alberti KG, Eckel RH, Grundy SM, et al. Harmonizing the metabolic syndrome: a joint interim statement of the International Diabetes Federation Task Force on Epidemiology and Prevention; National Heart, Lung, and Blood Institute; American Heart Association; World Heart Federation; International Atherosclerosis Society; and International Association for the Study of Obesity. Circulation 2009;120:1640-1645.

15. Nuver J, Smit AJ, Wolffenbuttel BH, et al. The metabolic syndrome and disturbances in hormone levels in long-term survivors of disseminated testicular cancer. J Clin Oncol 2005;23:3718-3725.

16. Wethal T, Kjekshus J, Roislien J, et al. Treatment-related differences in cardiovascular risk factors in long-term survivors of testicular cancer. J Cancer Surviv 2007;1:8-16.

17. de Haas EC, Altena R, Boezen HM, et al. Early development of the metabolic syndrome after chemotherapy for testicular cancer. Ann Oncol 2013;24:749-755.

18. Willemse PM, Burggraaf J, Hamdy NA, et al. Prevalence of the metabolic syndrome and cardiovascular disease risk in chemotherapy-treated testicular germ cell tumour survivors. Br J Cancer 2013;109:60-67.

19. Haugnes HS, Aass N, Fossa SD, et al. Components of the metabolic syndrome in long-term survivors of testicular cancer. Ann Oncol 2007;18:241-248.

20. Boer H, Westerink ND, Altena R, et al. Single-nucleotide polymorphism in the 5-alpha-reductase gene (SRD5A2) is associated with increased prevalence of metabolic syndrome in chemotherapy-treated testicular cancer survivors. Eur J Cancer 2016;54:104-111.

21. Fung C, Sesso HD, Williams AM, et al. Multi-institutional assessment of adverse health outcomes among North American testicular cancer survivors after modern cisplatin-based chemotherapy. J Clin Oncol 2017;35:1211-1222.

22. Travis LB, Andersson M, Gospodarowicz M, et al. Treatment-associated leukemia following testicular cancer. J Natl Cancer Inst 2000;92:11651171.

23. Taylor HL, Jacobs DR Jr, Schucker B, et al. A questionnaire for the assessment of leisure time physical activities. J Chronic Dis 1978;31:741755.

24. Chasan-Taber S, Rimm EB, Stampfer MJ, et al. Reproducibility and validity of a self-administered physical activity questionnaire for male health professionals. Epidemiology 1996;7:81-86.

25. Ainsworth BE, Haskell WL, Herrmann SD, et al. 2011 compendium of physical activities: a second update of codes and MET values. Med Sci Sports Exerc 2011;43:1575-1581.

26. Ridker PM, Hennekens $\mathrm{CH}$, Roitman-Johnson B, et al. Plasma concentration of soluble intercellular adhesion molecule 1 and risks of future myocardial infarction in apparently healthy men. Lancet 1998;351:88-92.

27. Ridker PM, Hennekens CH, Buring JE, Rifai N. C-reactive protein and other markers of inflammation in the prediction of cardiovascular disease in women. N Engl J Med 2000;342:836-843.

28. Mulvihill NT, Foley JB, Crean P, Walsh M. Prediction of cardiovascular risk using soluble cell adhesion molecules. Eur Heart J 2002;23:1569-1574.

29. Desroches B, Kohn TP, Welliver C, Pastuszak AW. Testosterone therapy in the new era of Food and Drug Administration oversight. Transl Androl Urol 2016;5:207-212.

30. Wheeler HE, Gamazon ER, Frisina R, et al. Variants in WFS1 and other Mendelian deafness genes are associated with cisplatin-associated ototoxicity. Clin Cancer Res 2017;23:3325-3333.

31. Howie B, Fuchsberger C, Stephens M, et al. Fast and accurate genotype imputation in genome-wide association studies through pre-phasing. Nat Genet 2012;44:955-959.

32. Machiela MJ, Chanock SJ. LDlink: a web-based application for exploring population-specific haplotype structure and linking correlated alleles of possible functional variants. Bioinformatics 2015;31:3555-3557.

33. Nordestgaard BG, Langsted A, Mora S, et al. Fasting is not routinely required for determination of a lipid profile: clinical and laboratory implications including flagging at desirable concentration cut-points-a joint consensus statement from the European Atherosclerosis Society and European Federation of Clinical Chemistry and Laboratory Medicine. Eur Heart J 2016;37:1944-1958.

34. Nottage KA, Ness KK, Li C, et al. Metabolic syndrome and cardiovascular risk among long-term survivors of acute lymphoblastic leukaemia-from the St. Jude Lifetime Cohort. Br J Haematol 2014;165:364-374.

35. Westerink NL, Nuver J, Lefrandt JD, et al. Cancer treatment induced metabolic syndrome: improving outcome with lifestyle. Crit Rev Oncol Hematol 2016;108:128-136.

36. Michelsen TM, Pripp AH, Tonstad S, et al. Metabolic syndrome after risk-reducing salpingo-oophorectomy in women at high risk for hereditary breast ovarian cancer: a controlled observational study. Eur J Cancer 2009;45:82-89.

37. Pietila S, Makipernaa A, Sievanen H, et al. Obesity and metabolic changes are common in young childhood brain tumor survivors. Pediatr Blood Cancer 2009;52:853-859. 
38. Meacham LR, Chow EJ, Ness KK, et al. Cardiovascular risk factors in adult survivors of pediatric cancer-a report from the childhood cancer survivor study. Cancer Epidemiol Biomarkers Prev 2010;19:170-181.

39. Rosen GP, Nguyen HT, Shaibi GQ. Metabolic syndrome in pediatric cancer survivors: a mechanistic review. Pediatr Blood Cancer 2013;60:1922-1928.

40. Smith MR, Finkelstein JS, McGovern FJ, et al. Changes in body composition during androgen deprivation therapy for prostate cancer. J Clin Endocrinol Metab 2002;87:599-603

41. Saylor PJ, Smith MR. Metabolic complications of androgen deprivation therapy for prostate cancer. J Urol 2009;181:1998-2006.

42. Shahani S, Braga-Basaria M, Basaria S. Androgen deprivation therapy in prostate cancer and metabolic risk for atherosclerosis. J Clin Endocrinol Metab 2008;93:2042-2049.

43. Guinan EM, Connolly EM, Healy LA, et al. The development of the metabolic syndrome and insulin resistance after adjuvant treatment for breast cancer. Cancer Nurs 2014;37:355-362.

44. Buttros Dde A, Nahas EA, Vespoli Hde L, et al. Risk of metabolic syndrome in postmenopausal breast cancer survivors. Menopause 2013;20:448-454.

45. Barrett-Connor E, Khaw KT. Endogenous sex hormones and cardiovascular disease in men. A prospective population-based study. Circulation 1988;78:539-545.

46. Khaw KT, Dowsett M, Folkerd E, et al. Endogenous testosterone and mortality due to all causes, cardiovascular disease, and cancer in men: European prospective investigation into cancer in Norfolk (EPIC-Norfolk) Prospective Population Study. Circulation 2007;116:2694-2701.

47. Kupelian V, Hayes FJ, Link CL, et al. Inverse association of testosterone and the metabolic syndrome in men is consistent across race and ethnic groups. J Clin Endocrinol Metab 2008;93:3403-3410.

48. Haring R, Volzke H, Steveling A, et al. Low serum testosterone levels are associated with increased risk of mortality in a population-based cohort of men aged 20-79. Eur Heart J 2010;31:1494-1501.

49. Li C, Ford ES, Li B, et al. Association of testosterone and sex hormonebinding globulin with metabolic syndrome and insulin resistance in men. Diabetes Care 2010;33:1618-1624.

50. Akishita M, Hashimoto M, Ohike $\mathrm{Y}$, et al. Low testosterone level as a predictor of cardiovascular events in Japanese men with coronary risk factors. Atherosclerosis 2010;210:232-236.

51. Araujo AB, Esche GR, Kupelian V, et al. Prevalence of symptomatic androgen deficiency in men. J Clin Endocrinol Metab 2007;92:4241-4247.

52. Bagatell CJ, Knopp RH, Vale WW, et al. Physiologic testosterone levels in normal men suppress high-density lipoprotein cholesterol levels. Ann Intern Med 1992;116(12 Pt 1):967-973.

53. Santosa S, Jensen MD. Effects of male hypogonadism on regional adipose tissue fatty acid storage and lipogenic proteins. PLoS One 2012;7:e31473.

54. Hildreth KL, Barry DW, Moreau KL, et al. Effects of testosterone and progressive resistance exercise in healthy, highly functioning older men with low-normal testosterone levels. J Clin Endocrinol Metab 2013;98:1891-1900.

55. Isidori AM, Giannetta E, Greco EA, et al. Effects of testosterone on body composition, bone metabolism and serum lipid profile in middle-aged men: a meta-analysis. Clin Endocrinol (Oxf) 2005;63:280-293.

56. Kloner RA, Carson C III, Dobs A, et al. Testosterone and cardiovascular disease. J Am Coll Cardiol 2016;67:545-557.
57. Basaria S, Coviello AD, Travison TG, et al. Adverse events associated with testosterone administration. N Engl J Med 2010;363:109-122.

58. Srinivas-Shankar U, Roberts SA, Connolly MJ, et al. Effects of testosterone on muscle strength, physical function, body composition, and quality of life in intermediate-frail and frail elderly men: a randomized, double-blind, placebo-controlled study. J Clin Endocrinol Metab 2010;95:639-650.

59. Ross R. Atherosclerosis-an inflammatory disease. N Engl J Med 1999;340:115-126

60. Ridker PM, Luscher TF. Anti-inflammatory therapies for cardiovascular disease. Eur Heart J 2014;35:1782-1791.

61. Vaughn DJ, Palmer SC, Carver JR, et al. Cardiovascular risk in long-term survivors of testicular cancer. Cancer 2008;112:1949-1953.

62. Shi $\mathrm{Y}$, Inoue $\mathrm{S}$, Shinozaki $\mathrm{R}$, et al. Release of cytokines from human umbilical vein endothelial cells treated with platinum compounds in vitro. Jpn J Cancer Res 1998;89:757-767.

63. Dirix LY, Libura M, Libura J, et al. In vitro toxicity studies with mitomycins and bleomycin on endothelial cells. Anticancer Drugs 1997;8:859-868.

64. Feldman DR, Schaffer WL, Steingart RM. Late cardiovascular toxicity following chemotherapy for germ cell tumors. J Natl Compr Canc Netw 2012;10:537-544.

65. Makridakis NM, di Salle E, Reichardt JK. Biochemical and pharmacogenetic dissection of human steroid 5 alpha-reductase type II. Pharmacogenetics 2000;10:407-413.

66. Hartz I, Eggen AE, Grimsgaard S, et al. Whom are we treating with lipid-lowering drugs? Are we following the guidelines? Evidence from a population-based study: the Tromso study 2001. Eur J Clin Pharmacol 2004;60:643-649.

67. National Cholesterol Education Program Expert Panel on Detection, Evaluation, and Treatment of High Blood Cholesterol in Adults (Adult Treatment Panel III). Third report of the National Cholesterol Education Program (NCEP) Expert Panel on Detection, Evaluation, and Treatment of High Blood Cholesterol in Adults (Adult Treatment Panel III) final report. Circulation 2002;106:3143-3421.

68. Expert Panel on Detection, Evaluation, and Treatment of High Blood Cholesterol in Adults. Executive summary of the third report of the National Cholesterol Education Program (NCEP) Expert Panel on Detection, Evaluation, and Treatment of High Blood Cholesterol in Adults (Adult Treatment Panel III). JAMA 2001;285:2486-2497.

69. Grundy SM, Cleeman JI, Daniels SR, et al. Diagnosis and management of the metabolic syndrome: an American Heart Association/National Heart, Lung, and Blood Institute scientific statement. Circulation 2005;112:2735-2752.

70. Lambers Heerspink HJ, Brantsma AH, de Zeeuw D, et al. Albuminuria assessed from first-morning-void urine samples versus 24-hour urine collections as a predictor of cardiovascular morbidity and mortality. Am J Epidemiol 2008;168:897-905.

71. Oterdoom LH, de Vries AP, Gansevoort RT, et al. Fasting insulin modifies the relation between age and renal function. Nephrol Dial Transplant 2007;22:1587-1592.

72. Brouwer CA, Postma A, Vonk JM, et al. Systolic and diastolic dysfunction in long-term adult survivors of childhood cancer. Eur J Cancer 2011;47:2453-2462. 